\title{
AN EXPERIMENTAL STUDY ON SAND DUNE SEDIMENT TRANSPORT DUE TO TSUNAMI OVERWASH
}

\author{
K M Ahtesham Hossain Raju ${ }^{1}$ and Shinji Sato ${ }^{2}$
}

\begin{abstract}
Response of sand dune when overwashed by tsunami or storm surge, is investigated by conducting small scale laboratory study. Dune consisting of initially wet sand and initially dry sand are tested for three different sand grain sizes. Overtopping of water and the corresponding sediment transport are analyzed. These data set can be used to validate mathematical models associated with dune sediment transport as well as prediction of dune profile.
\end{abstract}

Keywords: Overwash, Sand dune, Sediment transport

\section{INTRODUCTION}

Sand dune, an eco-friendly soft structure in the coasts mitigates the adverse effect of natural calamity like storm surge and tsunami by protecting the inland inhabitants, ecosystems and the infrastructure. Nowadays dune overwash has drawn the attention of many investigators which imply its increasing significance in coastal communities and habitat. Many dunes were collapsed by the 2011 Tohoku Tsunami by the onshore movement of the material. The transported sediment changes the adjacent morphology drastically. Therefore, spatial extent of protrusion, thickness of sediment layer over the land surface and volume of deposition is important for beach and dune design.

\section{BACKGROUND AND SCOPE}

Studies conducted for dune erosion on the foreshore side are abundant in literature while mited investigations are available for dune overwash (e.g. Raju and Sato 2015, Larson et al. 2009, and Tinh et al. 2008). Donnelly et al. (2006) suggested the necessity of comprehensive laboratory data sets to make a model capable of simulating various washover morphologies. Lack of data for wave overtopping and specially overwash of dune have been reported by Donnelly et al. (2006), Kobayashi et al. (2010), Figlus et al. (2011). Very little work has considered measurement of dune washover volume and hence, literature on comparison of landward sediment transport is scarce. However, there is still scope of research in the light of quantitative prediction of sediment transport during tsunami overwash. The present study focuses on the landward sediment transport due to bore overwash of dune.

There are scopes to improve the prediction of overwash rates of dune by laboratory investigation as mentioned by Kobayashi et al. (2010). Donnelly et al. (2006) claimed the necessity of comprehensive laboratory data sets to make a model capable of simulating various washover morphologies that have been produced by different mechanisms. Lack of data for wave overtopping have been reported by Donnelly et al. (2006), Kobayashi et al. (2010), Figlus et al. (2011), Baldock et al. (2012). Very little work has considered measurement of dune washover volume and hence, literature on comparison of landward sediment transport is scare. Initially dry and wet conditions of dune is examined because sand transport due to tsunami is different from that due to storm waves in the sense that tsunami may abruptly overwash the dune before it is saturated with sea water. The present study focuses on the landward sediment transport due to bore overwash of dune for initially dry sand and initially wet sand during overwash process.

\section{LABORATORY EXPERIMENT}

Small scale laboratory study has been conducted in the Hydraulics Laboratory of the Department of Civil Engineering, The University of Tokyo. Experiments were conducted in a $35 \mathrm{~m}$ long wave flume (Figure 1) equipped with a vertical gate to generate a bore over two bed slopes. Maintaining the same hydrodynamic conditions like- still water level in the flume $\left(\mathrm{h}_{1}\right)$, difference in water level to generate bore $\left(\Delta \mathrm{h}_{\mathrm{i}}: \Delta \mathrm{h}_{1}=6 \mathrm{~cm}, \Delta \mathrm{h}_{2}=8 \mathrm{~cm}, \Delta \mathrm{h}_{3}=10 \mathrm{~cm}\right)$ and same dune geometry (shape, height, width); bore overwash of dune take place for three sizes of sand individually. Three different grain sizes of sand $\left(\mathrm{d}_{50}=0.90 \mathrm{~mm}, 0.60 \mathrm{~mm}\right.$ and $\left.0.15 \mathrm{~mm}\right)$ were used to construct dunes by maintaining the same size and shape and following the same process for all the 16 experimental runs. For a particular sand grain size, initially dry sand dune and initially wet sand dune were constructed and separated by a thin vertical wall

\footnotetext{
1,2 Department of Civil Engineering, The University of Tokyo, 7-3-1 Hongo, Bunkyo-ku, Tokyo, 113-8656, Japan
} 
installed along the middle of flume. It facilitate to observe and analyze overwash process in wet and dry dune at a time for the same hydrodynamic condition. Details of the laboratory setup and properties of sand used in this study are mentioned in Raju and Sato (2015).

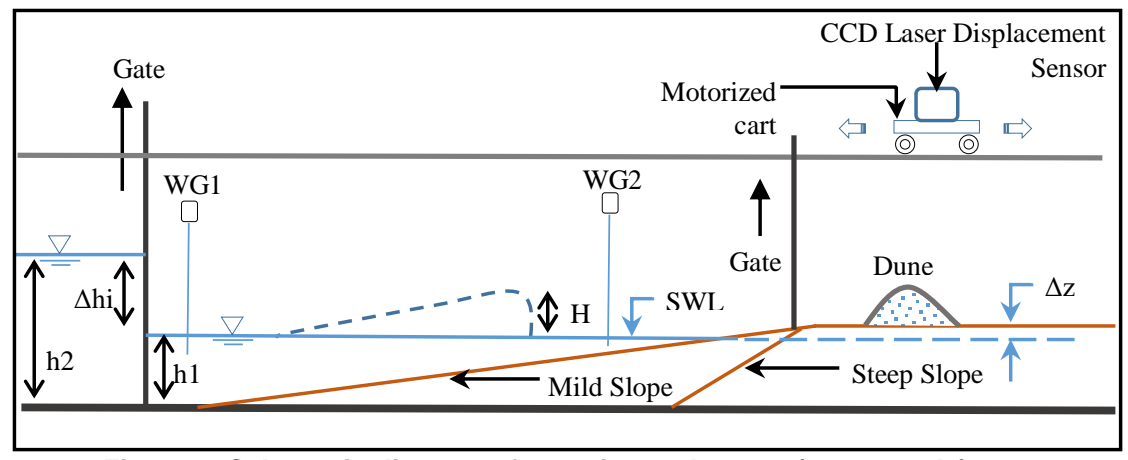

Figure 1. Schematic diagram of experimental set up (not to scale)

\section{Laser Displacement Sensor}

A high speed, high accuracy Charged Couple Device (CCD) Laser Displacement Sensor is employed in this study to collect the dune profile data before and after the experimental run as shown in Figure 2. The LK-G505 model has measurement accuracy of $\pm 0.001 \mathrm{~mm}$ and the sampling cycle of 200 $\mu \mathrm{s}$ with a storage cycle of $20 \mathrm{~ms}$. It is used as a profiler to collect the bed elevation data as well as dune profile data precisely. Therefore, the device is mounted on a motorized cart as shown in Figure 3.

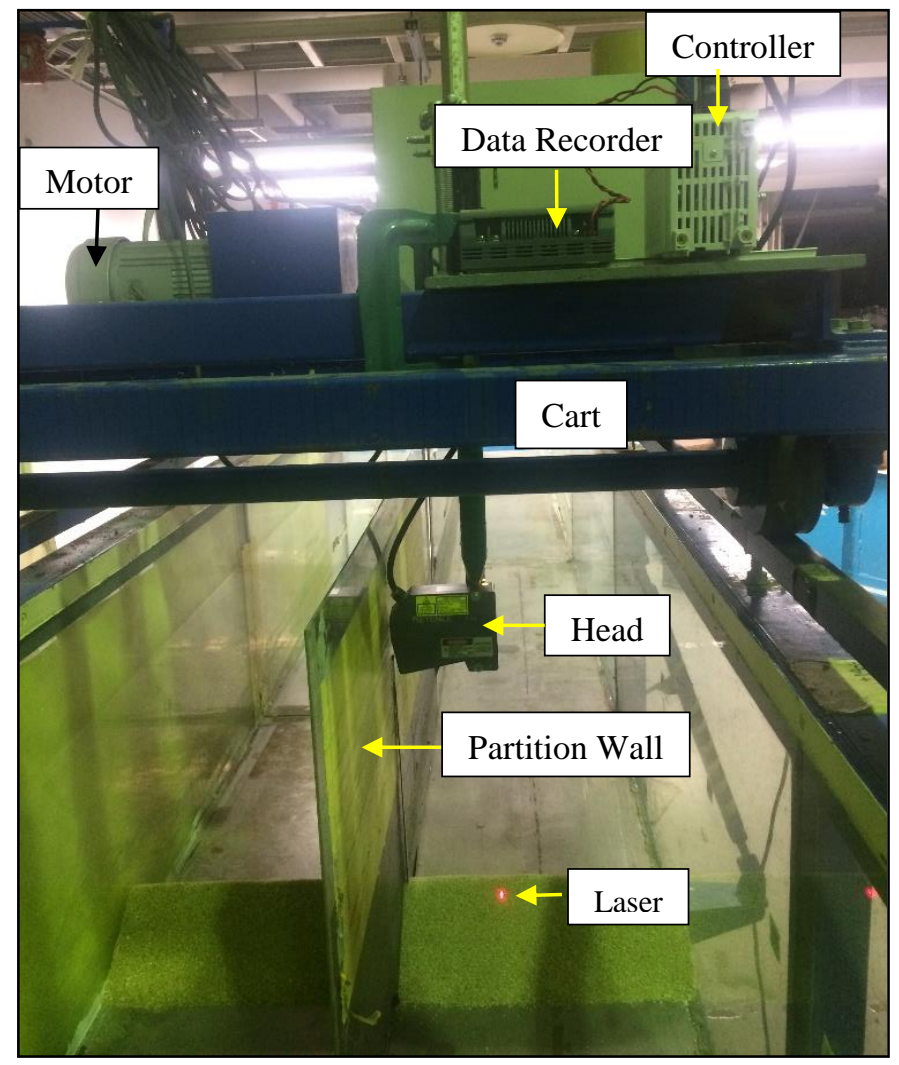

Figure 2. CCD Laser Displacement Sensor

\section{Data Collection Process}

Procedure of conducting the experiment is briefly mentioned below:

(i) Each dune is divided into five equal strip of $5 \mathrm{~cm}$ width across the shoreline as shown in Figure 4 and dune profile data is collected along these lines with CCD laser profiler before and after overwash occurs. 


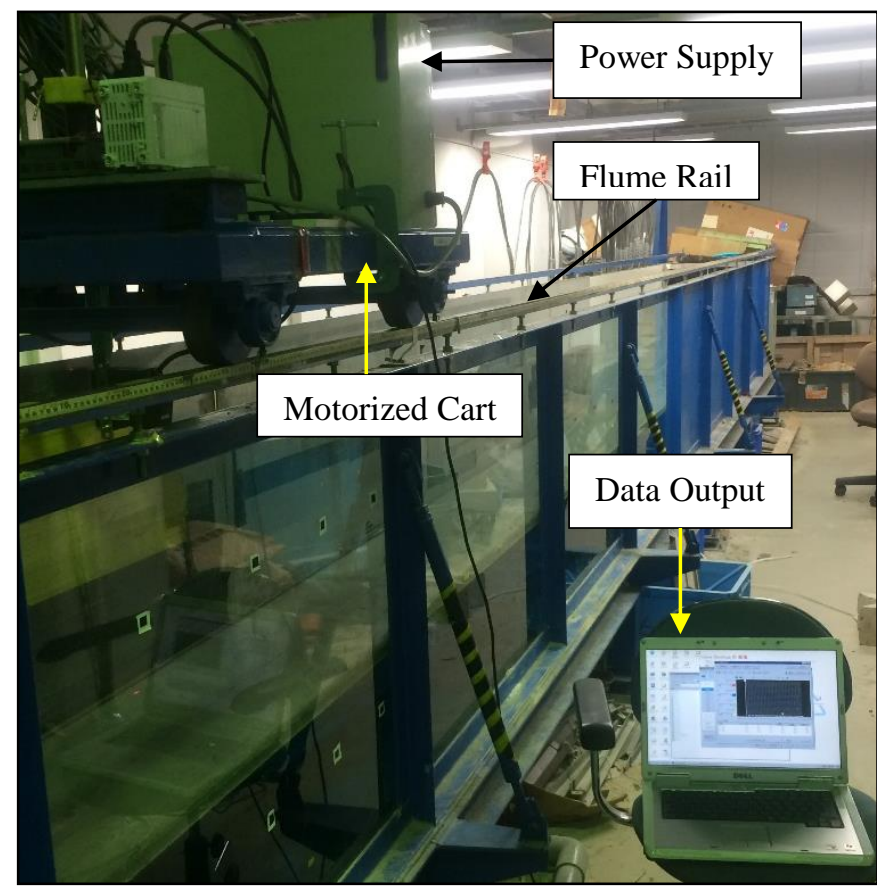

Figure 3. Motorized cart over the flume rail

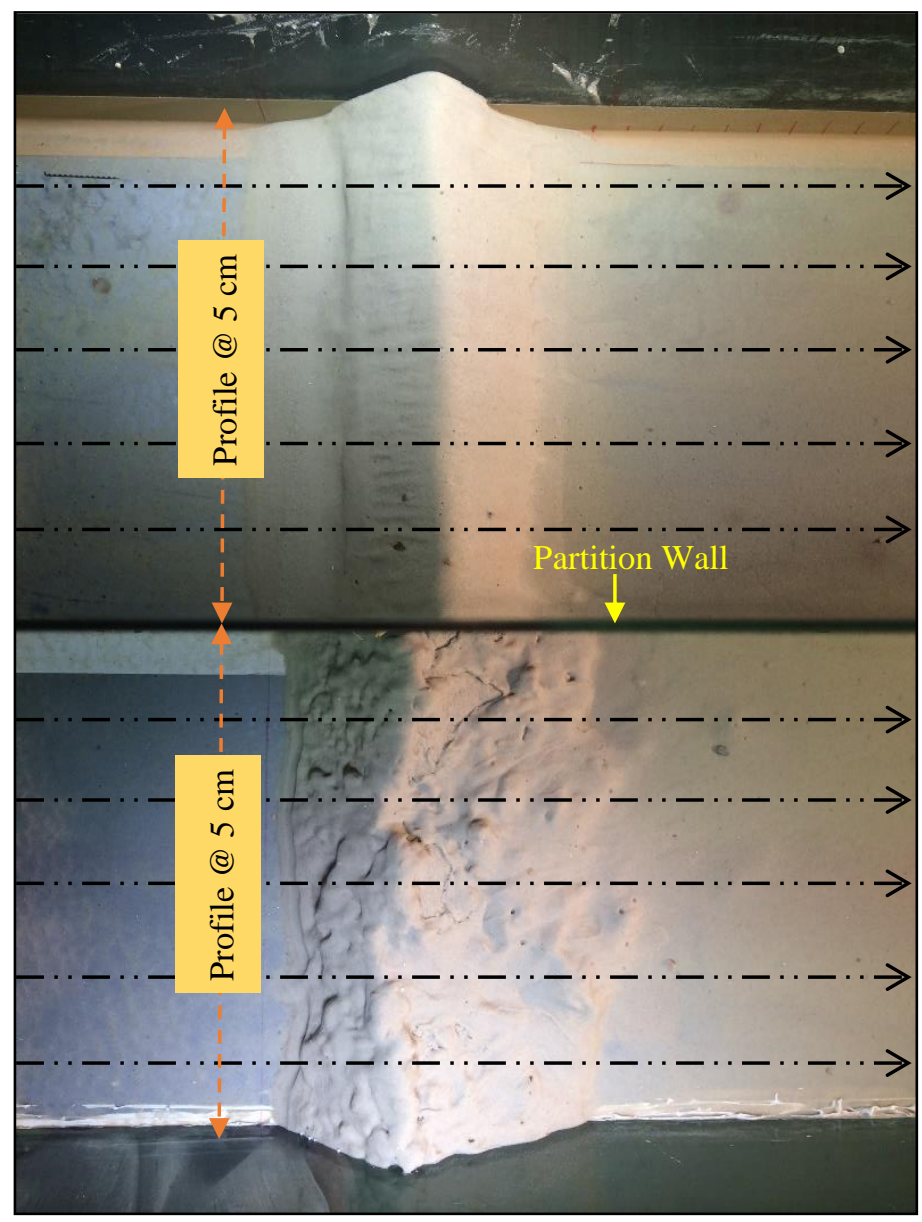

Figure 4. Lines along dune width for profile measurement 
(ii) High speed video camera are used on overhead of dune and by the flume wall to record the overwash process.

(iii) Then all sediment is collected on separate tray for initially wet and dry dune from the flume bed beginning from the back dune edge (Figure 5) of the initial dune till the farthest distance where sand grain moved.

(iv) The collected sediment is oven dried for 24 hours at $\pm 1050 \mathrm{C}$ and then the mass is measured on an electronic scale and recorded.

(v) Initial and final dune profile was plotted from the displacement sensor data. Detailed description of experimentation procedure is mentioned in Raju (2016).

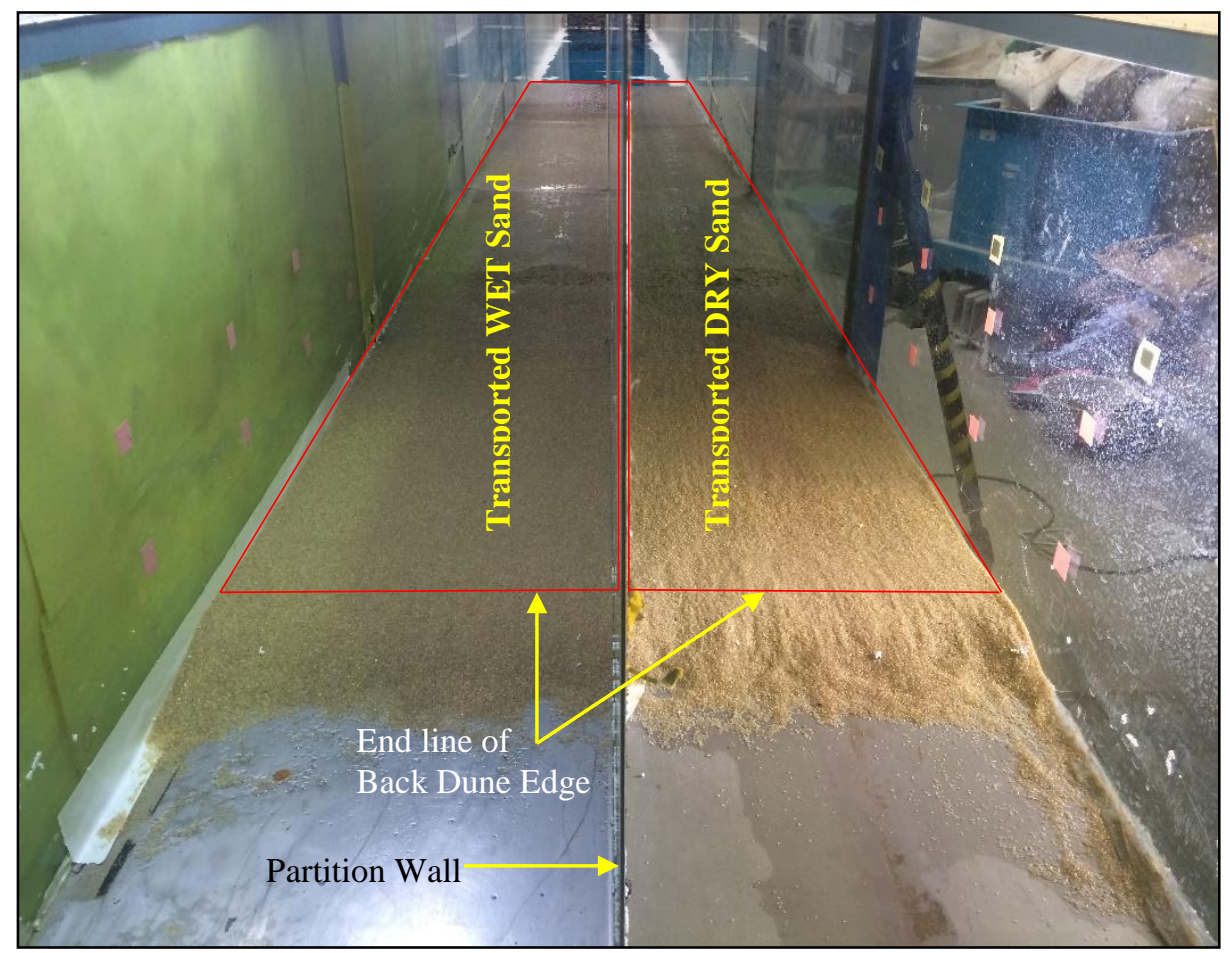

Figure 5. Transported sediment collection area (marked by red box) on the flume bed

\section{ANALYSIS}

The deformed shape of the dune depends on the grain size, bore height $(\mathrm{H})$, dune shape (however, in this study shape is same for all the experiments), initial water depth $\left(\mathrm{h}_{1}\right)$, and the elevation difference between dune foot and still water level $(\Delta z)$. Figure 6 shows erosion of dune crest and surface during experiment for the case of steep slope, medium sand and medium bore size $(\Delta \mathrm{hi}=8 \mathrm{~cm})$ while Figure 7 is an isometric view of overwashed dune.

The water overtopping rate is estimated using weir formula applied by Visser (1994). The formula is modified to recapitulate erodible dune phenomena considering the initial height of dune $\left(\mathrm{z}_{\mathrm{d}}\right)$ and water depth $\left(\mathrm{h}_{\mathrm{w}}\right)$; and remarkable final dune height $\left(\mathrm{z}_{\mathrm{d}}{ }_{\mathrm{d}}\right)$ and final water depth $\left(\mathrm{h}_{\mathrm{w}}{ }_{\mathrm{w}}\right)$ as shown in Figure 8. The word 'remarkable' implies that after attaining this condition, the dune sediment transport recedes to very small amount. Magnitude of these parameters are determined by analysis of recorded video and photo during the experimental run.

The modified formula can be stated as,

$q_{w}=m\left(\frac{2}{3}\right)^{\frac{3}{2}} \sqrt{g}\left[\frac{\left(h_{w}-z_{d}\right)+\left(h_{w}^{\prime}-z_{d}^{\prime}\right)}{2}\right]^{\frac{3}{2}}$

where $\mathrm{q}_{\mathrm{w}}=$ water overtopping rate, $\mathrm{m}=$ discharge coefficient $\cong 1$. 


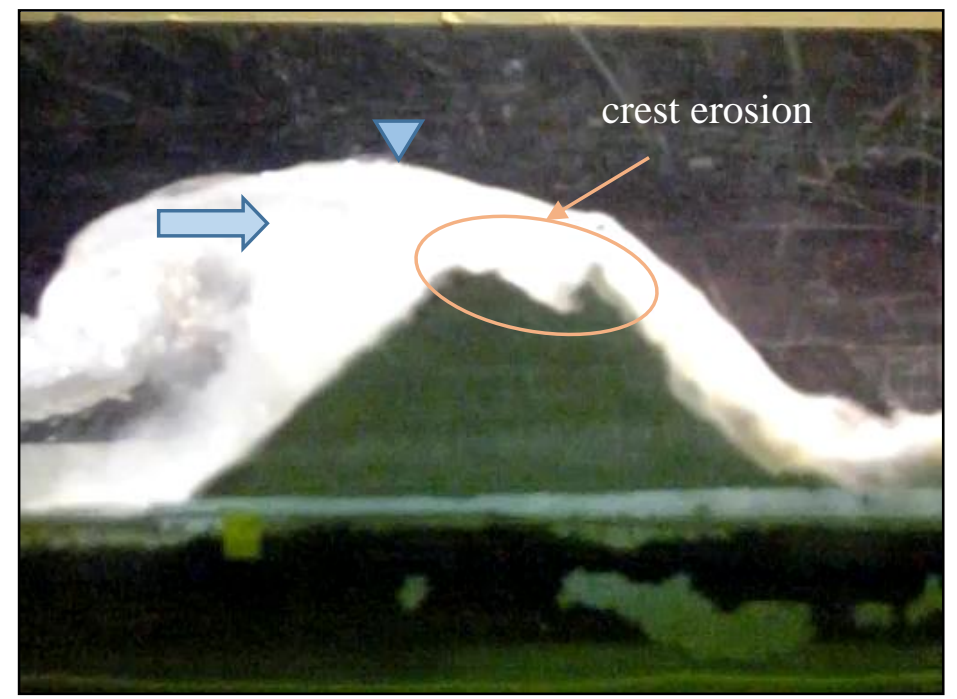

Figure 6. Water overflows sand dune during experiment in flume

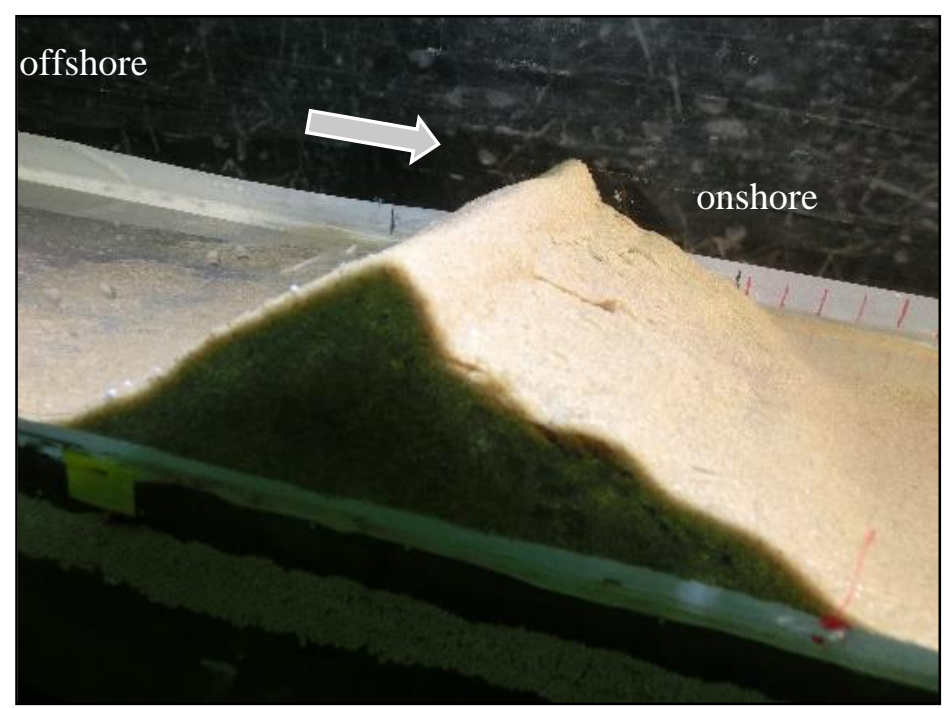

Figure 7. Isometric view of dune surface after overwash

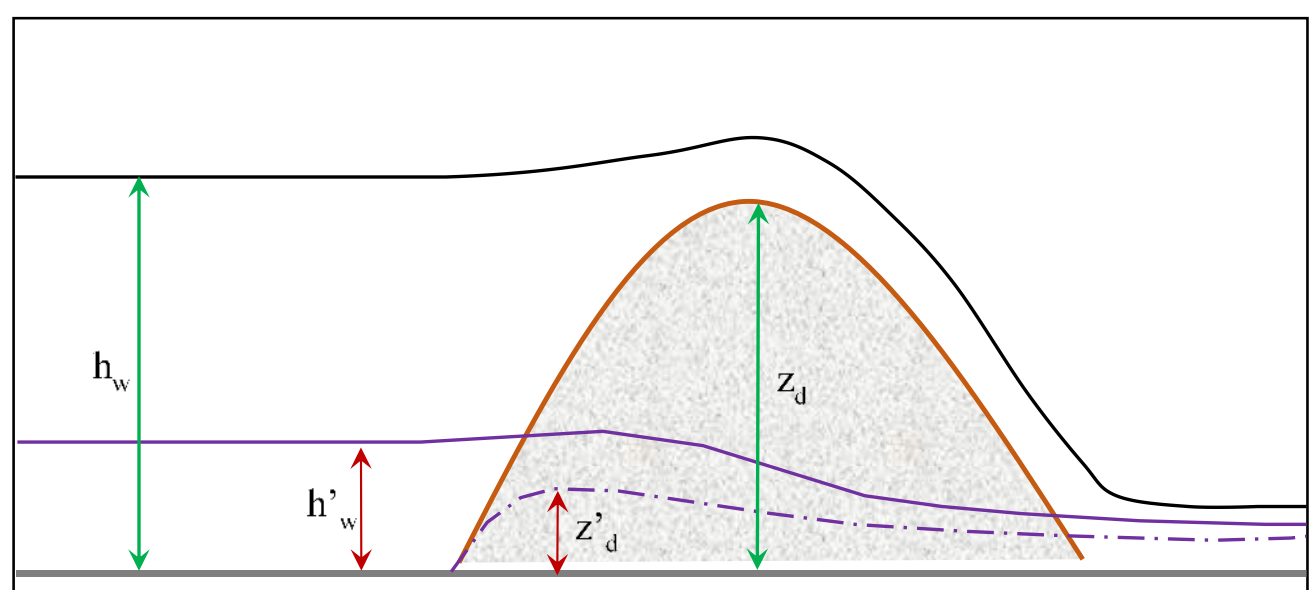

Figure 8. Schematic diagram representing water overtopping features

\section{RESULTS AND DISCUSSIONS}

Cross-sectional profile of overwashed dune of different sand grain sizes for the initially dry sand are shown in Figure 9 and that of initially wet sand are shown in Figure 10. The general trend of back dune surface reveals a milder slope in dry condition and relatively elevated crest in wet condition. The 
reasons may be, buoyancy is higher in initially wet sand causing more sand grains to move farther downstream resulting receding velocity to be increased, even though this velocity may be diminished earlier as the deformed crest height is higher. On the other hand, buoyancy in initially dry sand is less and water is absorbed by the dry sand and air voids are filled with water at the beginning of overwash causing a decelerated flow. This mechanism is important, even though this occurs within a short time. It is evident from these figures that wet fine sand has highest resistance potential against overwash while dry medium the least.

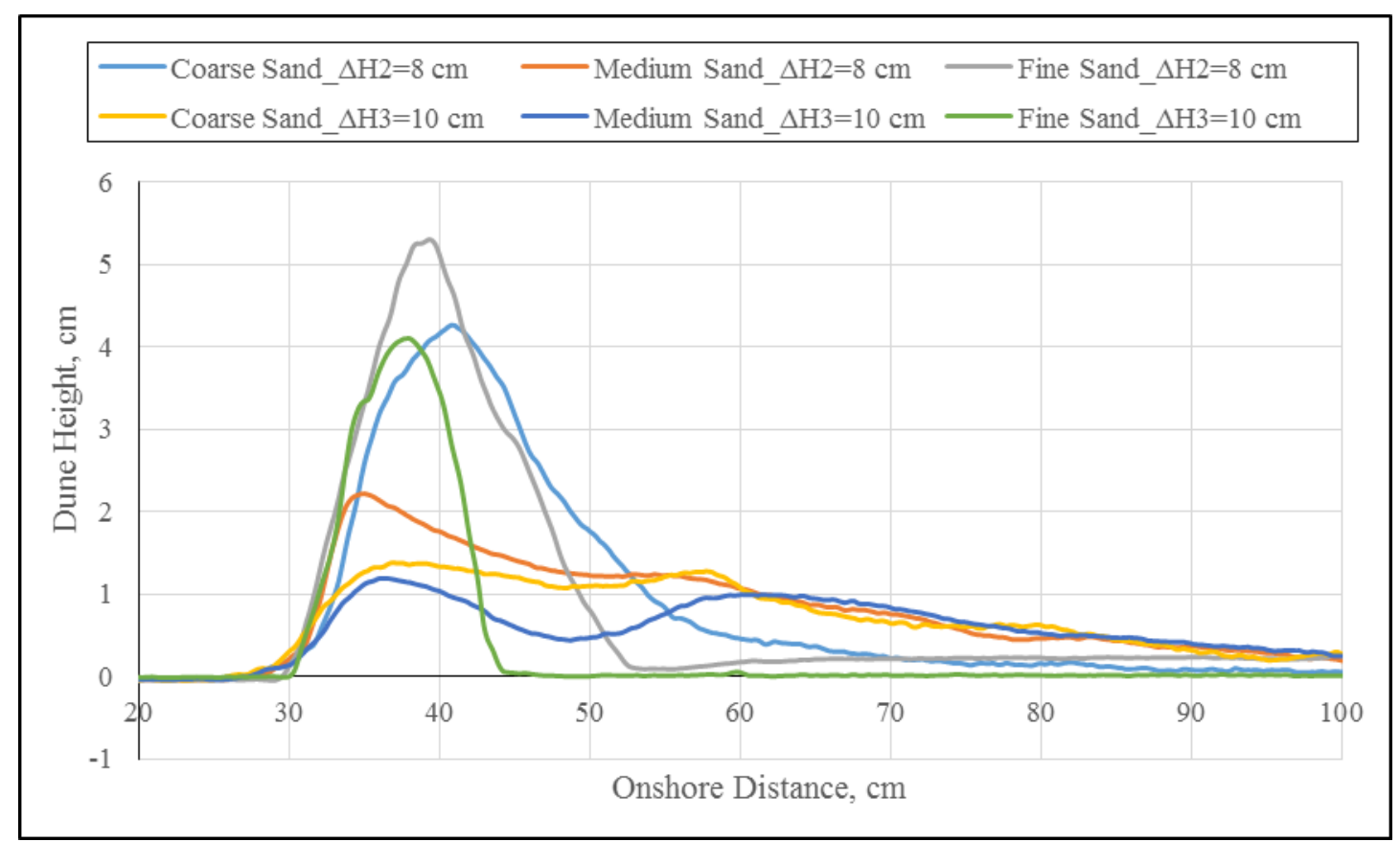

Figure 9. Overwashed profiles of initially dry sand dune

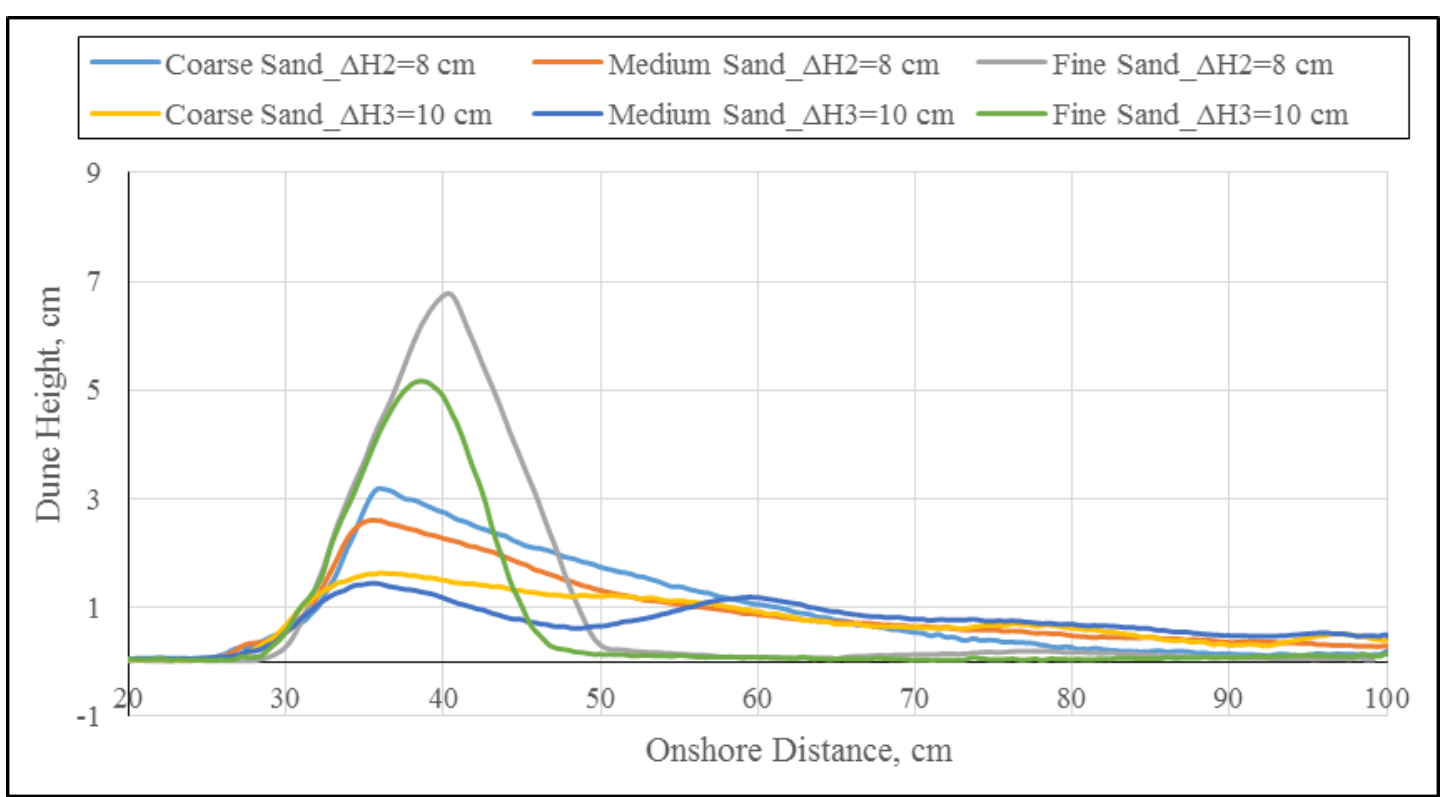

Figure 10. Overwashed profiles of initially wet sand dune

The proposed expression of Equation (1) is examined by considering three conditions to measure depth of water above dune crest: (i) only initial $\left(\mathrm{h}_{\mathrm{w}}-\mathrm{Z}_{\mathrm{d}}\right)$, (ii) only final $\left(\mathrm{h}^{\prime}{ }_{\mathrm{w}}-\mathrm{z}_{\mathrm{d}}{ }_{\mathrm{d}}\right)$ and (iii) average of initial and final $\left(\left(\mathrm{h}_{\mathrm{w}}+\mathrm{h}{ }_{\mathrm{w}}-\mathrm{Z}_{\mathrm{d}}-\mathrm{Z}_{\mathrm{d}}\right) / 2\right)$ to estimate $\mathrm{q}_{\mathrm{w}}$. Rate of overtopped water computed for these three conditions according to Equation (1) is plotted against depth of flow above dune crest as shown in Figure 11. Since the original formula considers a weir composed of non-erodible material, only initial 
condition $\left(\mathrm{h}_{\mathrm{w}}-\mathrm{z}_{\mathrm{d}}\right)$ gives the best estimation of $\mathrm{q}_{\mathrm{w}}$. A better estimation is obtained by taking average of initial and final water depth above dune crest. Since, in this study depth of water above the dune varies with time, therefore multiplying flow rate (computed by considering initial depth only) by total overwash duration will give overestimation of total water volume overtopped. Therefore, average of initial and final water depth above dune crest is preferable to predict water overtopping rate.

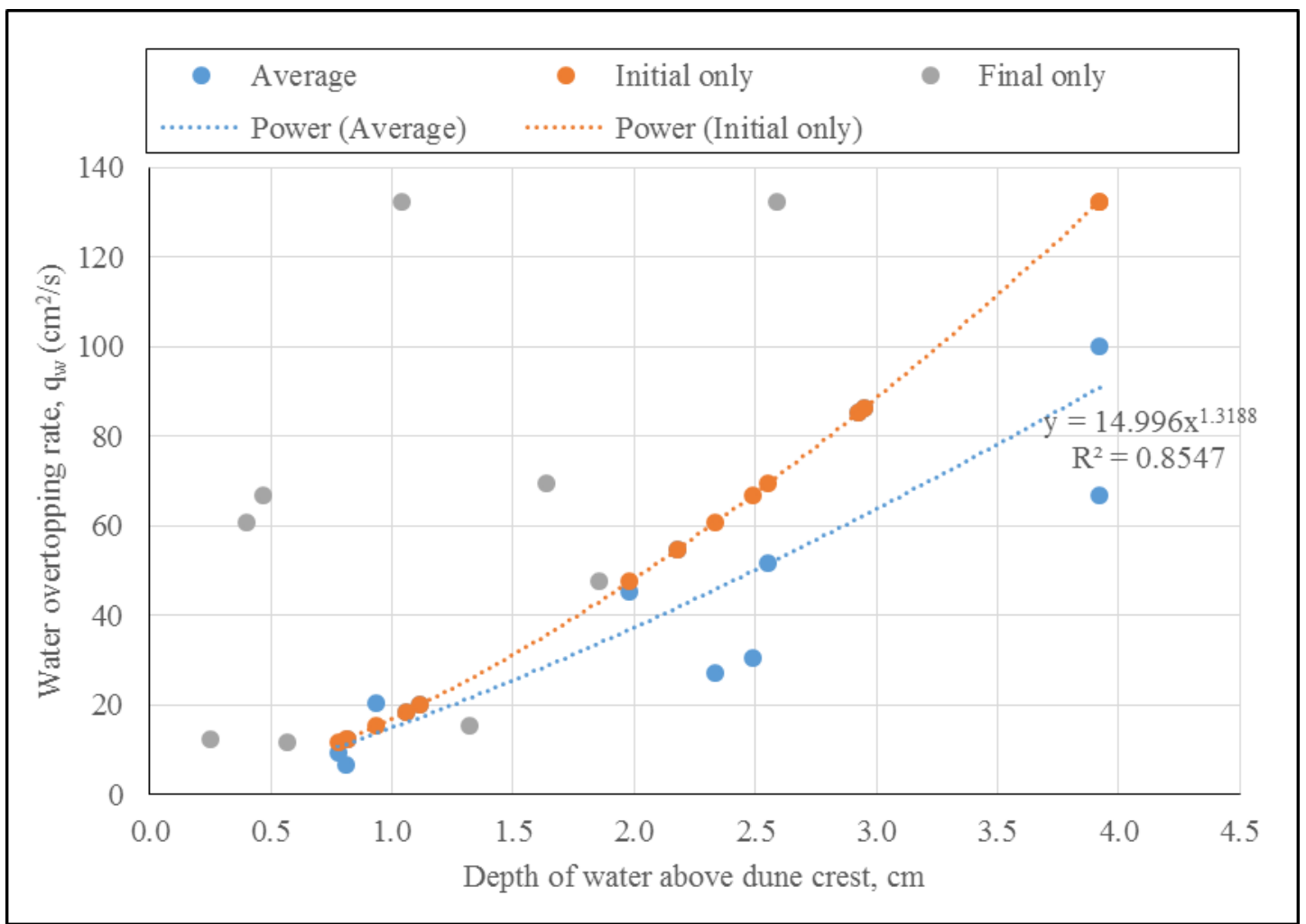

Figure 11. Water flow rate versus water depth above dune crest

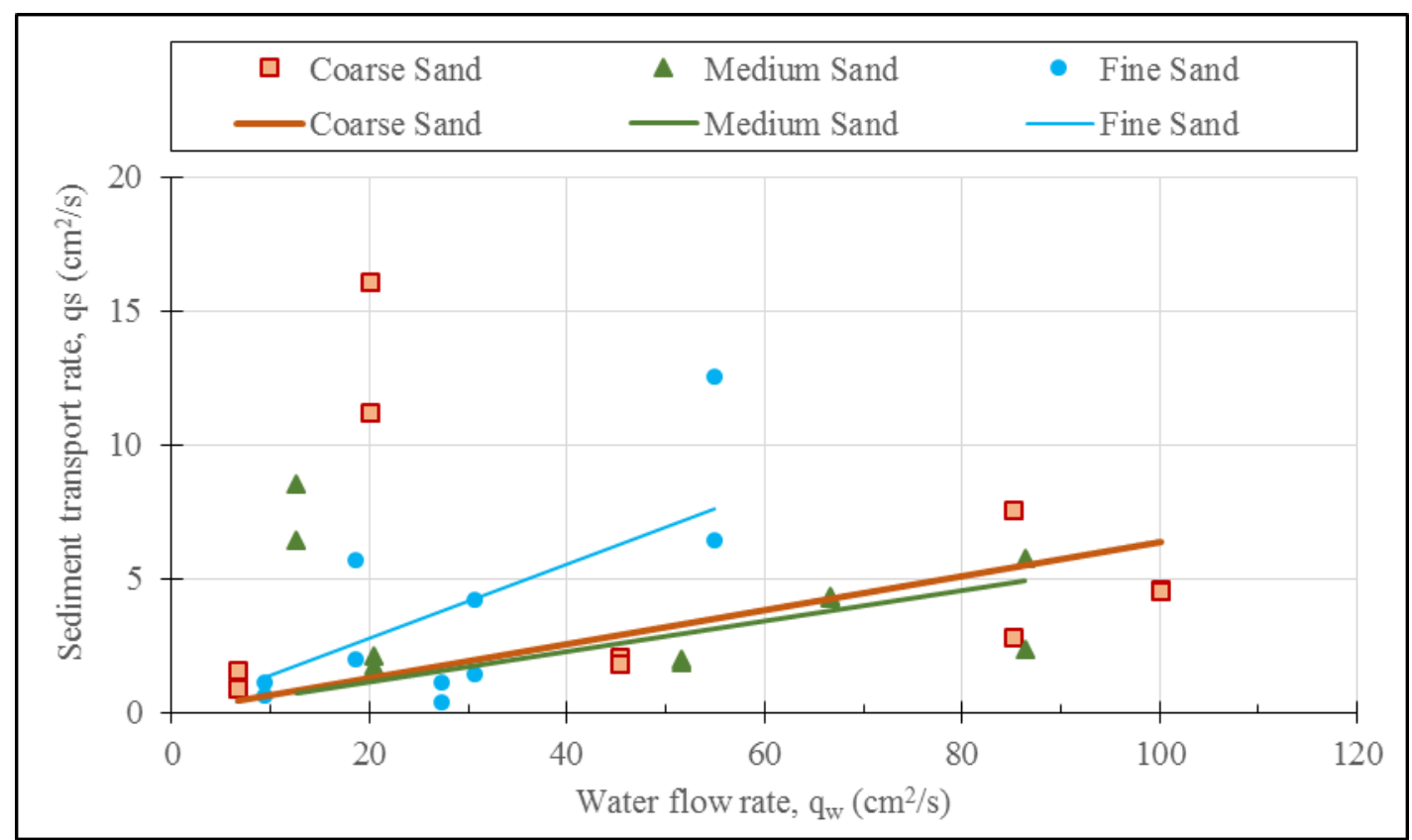

Figure 12. Water flow rate versus sediment transport rate for different sand 
It is assumed that volume of sediment transport in dry and wet condition is resulted from the same water overtopping volume. However, sediment transport rate is not the same. Table 1 shows computed values of water flow rate and measured values of sediment transport rate ( $\mathrm{q}_{\mathrm{sd}}$ for dry and $\mathrm{q}_{\mathrm{sw}}$ for wet). Figure 12 illustrate plot of water flow rate versus sediment transport rate for different sand. It is revealed that FS has a high rate due to small grain size. Figure 13 depicts water flow volume versus sediment transport volume for different sand. This shows higher volume transported for FS but interesting to note that almost same sediment volume is transported in CS and MS for a given volume of water.

\begin{tabular}{|c|c|c|c|}
\hline \multicolumn{3}{|c|}{ Table 1. Overtopping water flow rate and sediment transport rate for R1 to R16 } \\
\hline Run & $q_{w}\left(\mathrm{~cm}^{2} / \mathrm{s}\right)$ & $q_{s d}\left(\mathrm{~cm}^{2} / \mathrm{s}\right)$ & $q_{s w}=\left(\mathrm{cm}^{2} / \mathrm{s}\right)$ \\
\hline R1 & 20.1 & 11.2 & 16.1 \\
R2 & 12.6 & 8.5 & 6.4 \\
R3 & 18.5 & 5.7 & 2.0 \\
R4 & 85.3 & 7.5 & 2.8 \\
R5 & 86.4 & 5.7 & 2.3 \\
R6 & 54.9 & 12.5 & 6.5 \\
R7 & 100.1 & 4.6 & 4.5 \\
R8 & 66.7 & 4.3 & 4.3 \\
R9 & 30.7 & 4.2 & 1.4 \\
R11 & 6.6 & 0.9 & 1.5 \\
R12 & 20.5 & 2.1 & 1.7 \\
R13 & 9.4 & 1.1 & 0.6 \\
R14 & 45.4 & 2.0 & 1.8 \\
R15 & 51.6 & 1.8 & 2.0 \\
R16 & 27.2 & 1.1 & 0.4 \\
\hline
\end{tabular}

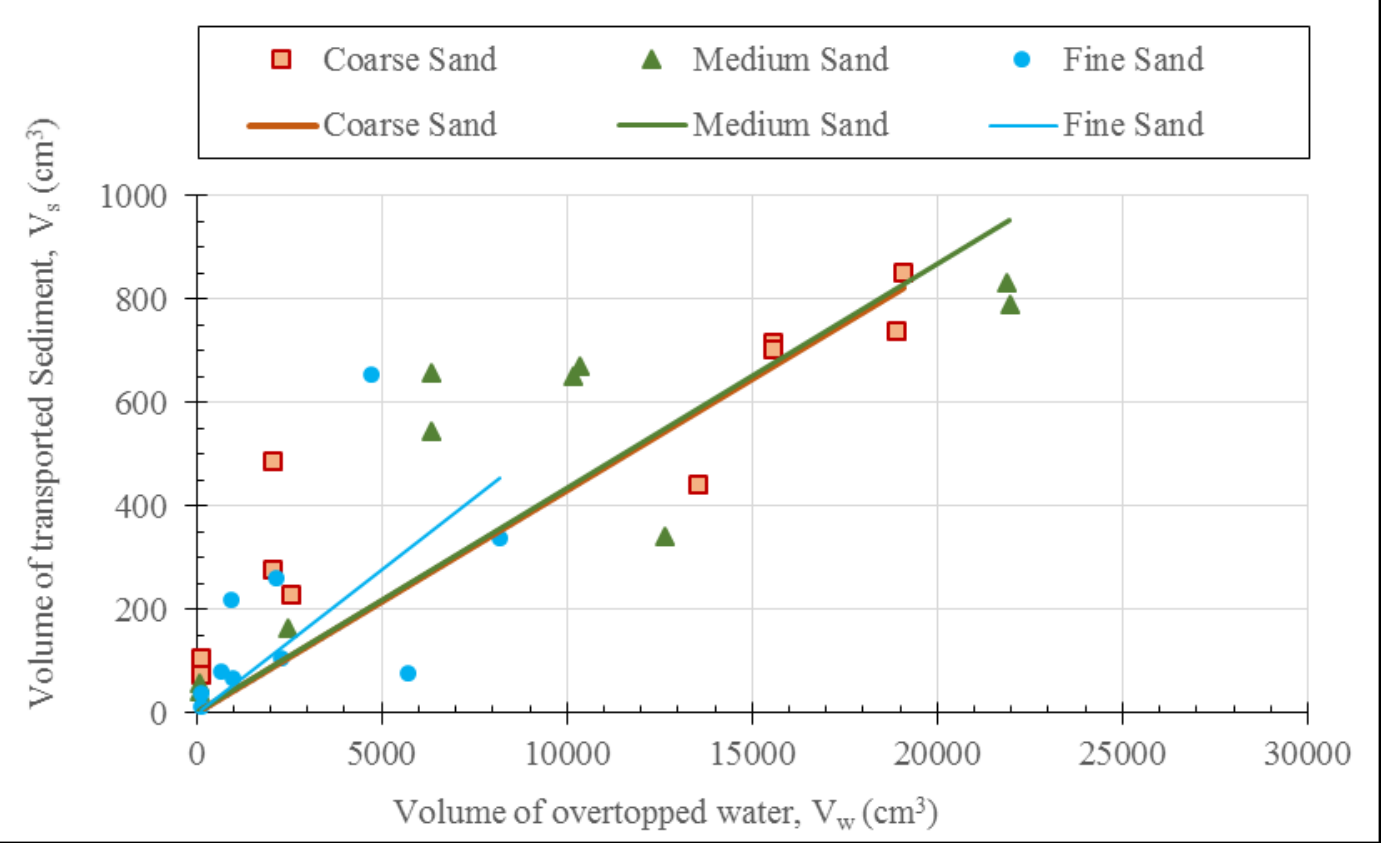

Figure 13. Water flow volume versus sediment transport volume for different sand 


\section{CONCLUSIONS}

Laboratory experiments were conducted for the investigation of predictive performance of sand dune sediment transport by overwash. Overwashed profile of sand dune are investigated based on grain size and initial dry/wet condition. Dune consist of fine sand for initially wet condition shows strong erosion resistance performance against overflow due to tsunami. Computation of overtopped water flow rate as well as volume of flow for erodible dune is examined. The data set presented here can be compared with the mathematical model outcome. Numerical modelling of hydrodynamics and dune morphology is in progress to come up with a better insight of the dune sediment transport due to tsunami overwash.

\section{ACKNOWLEDGMENTS}

The first author would like to express sincere gratitude to Japan Government for awarding the MEXT scholarship during the doctoral program in the Department of Civil Engineering, the University of Tokyo.

\section{REFERENCES}

Baldock, T. E., Peiris, D., and Hogg, J. A. 2012. Overtopping of solitary waves and solitary bores on a plane beach. Proceedings of the Royal Society A, 468, 3494-3516. Doi: 10.1098/rspa.2011.0729.

Donnelly, C., Kraus, N., and Larson, M. 2006. State of knowledge on measurement and modeling of coastal overwash, Journal of Coastal Research, 22(4), 965-991.

Figlus, J., Kobayashi, N., Gralher, C., and Iranzo, V. 2011. Wave overtopping and overwash of dunes, Journal of Waterway, Port, Coastal and Ocean Engineering, 137(1), 26-33.

Kobayashi, N., Farhadzadeh, A., Melby, J., Johnson, B., and Gravens, M. 2010. Wave overtopping of levees and overwash of dunes, Journal of Coastal Research, 26(5), 888-900.

Larson, M., Donnelly, C., Jimenez, J. A., and Hanson, H. 2009. Analytical model of beach erosion and overwash during storms, Proceedings of the Institution of Civil Engineers - Maritime Engineering, 2009, 162, No. 3, 115-125.

Raju, K. M. A. H. 2016. Sand dune erosion mechanism during tsunami overwash, PhD dissertation, Department of Civil Engineering, The University of Tokyo, Japan.

Raju, K. M. A. H, and Sato, S. 2015. An experimental investigation on influence of air void in sand dune sediment transport due to overwash, Proceedings of the Coastal Sediments 2015, 11-15 May, San Diego, CA, USA. (CD-ROM).

Tinh, N. X., Donnelley, C., Tanaka, H., and Larson, M. 2008. A new empirical formula for coastal washover sediment volume, Proceedings of the 31st International Conference on Coastal Engineering, pp. 1736-1748.

Visser, P. J. 1994. A model for breach growth in sand-dikes. Proceedings of the 24th International Conference on Coastal Engineering, pp. 2755-2769. 